\title{
Superfoods: Big Focus on Honeybee Pollen in Korea and Japan
}

\author{
Ventura Coll Francesc* \\ Department of Business Development, Mondelēz International \& Catalan Food Science Association (ACCA), Barcelona, Spain
}

*Corresponding author: Ventura Coll Francesc, Department of Business Development, Mondelēz International \& Catalan Food Science Association (ACCA), Barcelona, Spain, Email: Fventuracoll@gmail.com

To Cite This Article: Ventura Coll Francesc. Superfoods: Big Focus on Honeybee Pollen in Korea and Japan. Am J Biomed Sci \& Res. 2019 - 4(4). AJBSR.MS.ID.000805. DOI: 10.34297/AJBSR.2019.04.000805

Received: July 24, 2019 | Published: August 05, 2019

\begin{abstract}
SUMMARY
Honeybee pollen has traditionally considered a food of nutritional interest as a source of free essential amino-acids and proteins, carbohydrates and vitamins. The biochemical research on honeybee pollen carried out and published by Josep Serra Bonvehí and Francesc Ventura Coll lead to medical studies "in vitro" and "in vivo" in Japan and South Korea. Honeybee pollen is well known as a nutritional complement but not so well are its preventive and therapeutic effects. For this reason, the television channel MBN from South Korea, which produces TV programs on healthy life, came to Barcelona to film the work in laboratory and to make an interview, the content of which is developed here.
\end{abstract}

Keywords: Honeybee collected pollen; Flavonoids; Rutin; Quercetin; Kaempherol; Hypotensive; Anti-imflammatory; Antoxidant

Interview of MBN TV Channel (Maekyung Media Group, Seoul; South Korea) To Francesc Ventura Coll

\section{MBN TV Channel}

Producers: Hae-Yeon Kim (MBN Channel, www.mbn.co.kr); Kim Sang-Bok (WildNet); Organizer, doctor and translator: Choe Taewon.

\section{Interviewed person: Francesc Ventura Coll (FVC)}

a. Question MBN: What aspects of composition and quality of pollen would you highlight?

Answer FVC: Bees collect pollen from certain flowers as a nutritional source of protein, glycosides and flavonoids, sterols, carotene and lycopene, tocopherols (E vitamin), minerals and make it in the spherical form we know. The botanical origin is responsible for the yellow, orange or purple tones. Pollen which is rich in rock-rose (Cistus sp) and particularly Cistus ladaniferus are the most interesting. They contain pollen from Cistus present up to $80 \%$, but at the same time they can have up to 52 different pollinic forms, among which Echium plantagineum, (viper's bugloss), Quercus sp. (holm oaks and oaks), Erica lusitanica (heather) and Helianthemum sp (rock-rose species) How the process to dry the pollen is done is important in order to have the highest protein quality. If drying is not well done, proline, an amino-acid of low protein value increases [1,2]. And the botanical origin also de termines the quality: Chinese pollen, for example, cannot meet the minimum of $2 \%$ of free amino acids, which is one of the standards for EU pollen.

b. Question MBN: What are the components of pollen that give health benefits such us flavonoids and what effects produce?

Answer FVC: The pollen of rock-rose are rich in flavonoids: quercetin, rutin, kaempherol and catechins, which have synergistic effects with phytosterols, all considered hypotensive, anti-inflammatory and antioxidant. Quercetin and rutin are two of the main components of which medical studies have been performed $[3,4]$.

c. Question MBN: What active principle would you choose as functional quality characteristic of honeybee pollen?

Answer FVC: It turns out that the shape of the Cistus pollen (Cistaceae, rock-rose) can be easily confused with the shape of the Citrullus pollen (Cucurbits, watermelon), which abounds in the Chinese honey bee pollen [5], with the problem that contains less active principles. For this reason, we propose a quality indicator of at least 200 milligrams per kilo of the rutin component, a value that is accomplished in the Iberian honeybee pollen, but not in the Chinese honeybee pollen. 
d. Question MBN: Which effects produces rutin in the health of blood vessels, principally capillary?

Answer FVC: The beneficial effects of pollen on the cardiovascular system are related to phytosterols and flavonoids, especially rutin. The medical effects have been demonstrated with pollen hydrolizates, capable of converting an enzyme from our body, angiotensin I into angiotensin II (ACE), which lowers blood pressure [6].

e. Question MBN: Explain about the anti-inflammatory effect produced by honeybee pollen?

Answer FVC: Medical tests have determined the anti-inflammatory mechanism, which is due to the inhibition of 2 enzymes, cyclooxygenase (COX) and lipoxygenase, responsible for the appearance of some substances that cause pain and inflammation, prostaglandins and leukotrienes. Improvement has been confirmed in patients with benign prostatic hyperplasia (BPH) who followed a supplemented diet with pollen for 3 months [7].

\section{f. Question MBN: Any other healthy benefit from pollen?}

\section{Antioxidant effect?}

Answer FVC: Oxidative stress is commonly associated with autoimmune disorders, cataracts, arthritis, cardiovascular diseases. Honeybee pollen and propolis activate glutathione-peroxidase and reductase antioxidant enzymes in our body. The antioxidant potential can be chemically measured with TEAC, "Trolox equivalent antioxidant capacity", (unit: $\mu \mathrm{mol}$ Trolox/g), the higher the better. Honeys are usually between 2 and 6, the pollen around 17 and propolis depending on its origin and composition could be between 200 and 1400. Although propolis is always consumed diluted, with honey for instance, this demonstrate the antiox potential of these natural products [8].

g. Question MBN: Intake directions (or possible future use) given its value as functional food?

Answer FVC: In accordance with European legislation (EU Regulation 1924/2006) honeybee pollen is considered a functional food, admitting "claims" such as: a) improving the physical state; b) improvement of digestion, intestine and liver. Pollen has also a prebiotic effect, increasing Lactobacillus spp.
Directions: Between 20 grams and 50 grams of pollen are recommended as daily intake, better before meals. Two spoons of dessert before breakfast are about 20 grams.

h. Question MBN: Short conclusion, mention or opinion about honeybee pollen?

Answer FVC: Rock-rose does not produce nectar, therefore there is no honey from this origin. But we do have the great luck to be able to have pollen of this origin, which is a natural product that contains a concentration of important active principles. Japanese medical studies talk about "cell markers", that is, substances that can induce a positive effect. In this sense it would be very interesting to obtain a "hydrolyzed" pollen, in which active principles could be released more easily, together with the protein nutritional value it already contains. In Japan, they work firmly on this.

\section{References}

1. Serra-Bonvehí J, Escolà-Jordà R (1997) Nutrient composition and microbiological quality of honeybee-collected pollen in Spain. J Agric Food Chem 45: 725-732.

2. Serra-Bonvehí J, Gonell-Galindo J, Gomez-Pajuelo A (1986) Estudio de la composición y características físico-químicas del polen de abejas. Alimentaria 176 (October): 63-67.

3. Serra-Bonvehí J, Ventura-Coll F (2000) Study on Propolis quality from China and Uruguay. Z Naturforsch 55(9-10): 778-784.

4. Serra-Bonvehí J, Soliva-Torrentó M, Centelles-Lorente E (2001) Evaluation of polyphenolic and flavonoid compounds in honeybee-collected pollen produced in Spain. J Agric Food Chem 49(4): 1848-1853.

5. Yang K, Wu D, Ye X, Liu D, Chen J, et al. (2013) Characterization of chemical composition of bee pollen from China. J Agric Food Chem 61(3): 708718.

6. Nagai T, Inoue R, Suzuki N, Tanoue Y, Kai N, et al. (2007) Antihypertensive activities of enzymatic hydrolysates from honeybee-collected pollen of Cistus ladaniferus. J Food Agric Env 5(3\&4): 86-89.

7. Maruyama H, Sakamoto T, Araki y, Hara H (2010) Anti-inflammatory effect of bee pollen etanol extract from Cistus sp. of Spain on carrageenan-induced rat hind paw edema. BMC Complement Altern Med 10: 30.

8. Nagai T, Inoue R, Suzuki N, Myoda T, Nagashima T, et al. (2005) Antoxidative ability in a linoleic acid oxidation system and scavenging abilities against active oxygen species of enzymatic hydrolizates from pollen Cistus ladaniferus. Int J Mol Med 15(2): 259-263.

9. Regulation (EC) No 1924/2006 of the European Parliament and of the Council of 20 December 2006 on nutrition and health claims made on foods. Europe p 9-25. 